\title{
The Possibilities of Blockchain Technology in Medicine (Review)
}

\author{
DOI: $10.17691 / \mathrm{stm} 2019.11 .4 .21$ \\ Received April 22, 2018
}

A.A. Litvin, MD, DSc, Professor, Department of Surgical Disciplines ${ }^{1}$;

S.V. Korenev, MD, DSc, Professor, Director of Medical Institute ${ }^{1}$;

E.G. Knyazeva, Leading Manager of the Main Educational Programs, Medical Institute'; V. Litvin, Developer's Board Member ${ }^{2}$

${ }^{1}$ Immanuel Kant Baltic Federal University, 14 A. Nevsky St., Kaliningrad, 236016, Russia;

${ }^{2}$ Cyber Congress, 600 Travis St., Suite 6160, Houston, Texas, 77002, USA

\begin{abstract}
A blockchain technology representing a tool for data storage and transmission is briefly described in this review. Current trends of its development are also shown as well as currently known specific features and advantages of using the blockchain technology in medicine. The possibilities and prospects of applying the blockchain for solving some tasks in healthcare are analyzed. In addition, shortcomings and problems associated with the employment of this technology in medicine are also highlighted.

Though the majority of the projects for using the blockchain in medicine are now being only developed, a sufficient number of them have already been realized, there have appeared applications in blockchain. An interdisciplinary approach and collaboration of physicians with blockchain specialists will provide the opportunity to use the rapidly evolving digital technologies in the field of medicine.
\end{abstract}

Key words: blockchain; blockchain technology; blockchain in medicine; information technologies in healthcare.

\section{Introduction}

First applications of a blockchain technology (BT) became known in 2009 due to the development of a bitcoin cryptocurrency by a programmer Satoshi Nakamoto whose identity remains unknown [1]. The financial crisis of 2008 promoted in many respects the success of the bitcoin. People have lost credit to the bank and controlled financial organizations. Bitcoin suggested independence from public or any other centralized impact. This attribute was achieved owing to the application of the BT [2].

The blockchain technology is gradually changing the world just as Internet has recently done it. The interest in this technology is growing every day and there exists an opinion that in the near future all industries in the world will have to use the technologies connected with a blockchain [3]. The BT is called a "future Internet" predicting its fundamental role in the transformation from the internet of information sharing to the internet of value exchange [4].

At present, the BT is considered as part of the fourth industrial revolution which includes the invention of the steam engine, discovery of electricity, and the development of information technologies [5]. Owing to the properties such as immutability, transparency, and reliability of all operations performed in a blockchain, this innovative technology has a lot of potential possibilities for its application $[6,7]$. It made it possible to create decentralized distributed public information systems where the consensus on the state of the distributed ledger is achieved due to the economic stimuli built in these systems. The BT has gained the most widespread usage in the financial sphere [1, 3, 8-11], trade [12-19], there are reports on the successful implementation of the technology into the system of education [20-26], decentralized cloud data storage [27-29], in the systems of electronic voting [30-32] and intellectual property protection [33-35], etc.

In this review, the possibilities of using BT in medicine have been considered. The following online databases were used to search for the literature for this article: PubMed using a "blockchain" search string [all fields] and "health" [MeSH Terms] or "health" [all fields]; eLibrary using "блокчейн" (blockchain) and "медицина" (health) as key words. Searching has been performed from April 2018 till October 2019. The publications were then considered based on certain criteria of inclusion or exclusion. All works published in medical journals on the problem of the BT application in medicine or healthcare have been included. Besides, the materials on the BT accessible on Google Scholar and ResearchGate have been also used.

\section{The main blockchain terms}

According to Wikipedia, blockchain, or originally block chain, is a continuous successive chain of blocks (a linked list) arranged according to definite rules and containing information. Commonly, the copies of block chains are stored in a great number of different computers independently of each other [36]. A more

Corresponding author: Andrey A. Litvin, e-mail: alitvin@kantiana.ru 
clear definition is likely to be derived from the original designation of the BT [6]. Initially the blockchain was designed within the frames of solving quite a specific task, i.e. construction of a decentralized (without a single control center) financial system with any participant able to verify the correctness of its work. On this basis the blockchain can be defined as a way of storage and coordination of a database the copy of which is available to each network participant. The following conditions are observed: 1) the number of the participants is unknown; 2) the participants are anonymous; 3 ) the participants do not often trust each other; each transaction must be validated by the majority [37].

Initially, the term "blockchain" originated from the method of information storage in the "Bitcoin" system. All transactions with the bitcoin are stored in a grouped form (transaction groups are called blocks). And each successive block contains a hash reference (a digital print) of the preceding one. In this way, a chain of blocks is originated; the blocks of transactions are inseparably linked with each other, and each new one is connected with the previous which cannot be changed without changing the new blocks. In fact, the blocks may be compared with pages in a note-book where each record has its order number. When the page is completed, numbering is continued on the next page. In this way, the continuity of all records from the first to the last can be verified [37].

The key feature of the accounting system of BT transactions consists in its functioning as an independent system. It does not have any central authority, organization, or administrator which would control it. The system is completely transparent and works on the principle of business logic defined within the frames of the protocol. The entire history of transactions is accessible by everyone but could not be altered without reaching consensus. It is explained by the connectivity of the blocks: if the record is changed in one block, the continuity of all successive ones is broken. The current cryptographic algorithms secure impossibility to evade these rules [37]. The technological breakthrough of the BT consists just in the fact that a mathematically provable method of creating a system which works under such conditions has been found. Therefore, this technology ideally suits the cases in which the members cannot principally trust each other by $100 \%$ but work on the accounting of the same data [8].

At present, the term "blockchain" may imply different things. Bitcoin enthusiasts think of "bitcoin-blockchain", as a database which stores the logs on transactions with bitcoin [38-40]. Those who work in the financial sphere speak of the blockchain as a revolutionary technology capable of changing the financial world [12, 19, 41-43]. The rest assess the possibilities of realizing the BT in a concrete field of application: in commerce [44-46], education [24-26, 47], healthcare [12, 48-54], or within the frames of specific tasks: Internet of things [55], stock exchanges and crowdfunding [3], transfer of payments
[56], management of delivery chains [57], contract sector [58], etc.

Blockchains are divided into: 1) public/private; 2) permissioned/permissionless; 3 ) by the mechanism of gaining consensus [12, 14, 59, 60]. In the public blockchain, anyone can have access to transactions and carry out an audit, in the private one only a predetermined party may possess these rights. The permissionless blockchains allow anyone to become a validator (miner, participant of the verification) and create new blocks, in the permissioned ones only specially designated parties may verify transactions and generate the blocks.

A consensus protocol is a process by which a network of computers may come to an unambiguous solution aimed mainly to reduce the risks of forming an alternative blockchain, closing the network, or censoring some users.

Consensus "proof-of-work": 1) the number of participants is unknown; 2) the participants are anonymous and do not have a reputation; 3) a vote is validated by the proof of work; 4) consensus has been achieved if the parties which control the highest computational power came to the consensus.

Consensus "proof-of-stake": 1) the block developer is determined by the algorithm; 2) the chance to vote is proportional to the balance; 3) the participant loses his stakes if he validates incorrect or conflicting blocks; 4) consensus is reached if the owners of most stakes managed to coordinate the database status.

Consensus BFT (the Byzantine fault tolerance): 1) the number of participants is already known; 2) the participants are identified and know each other; 3) addition or removal of a participant requires agreement of the rest.

Consensus FBA (federated Byzantine agreement): participants are equal, not anonymous, the number is not fixed; 2) participants chose only those whom the trust; 3) participants form the groups in which they gain consensus; 4 ) as the groups are crossed consensus is reached among all participants [61-63]. The last two consensuses are mainly used in designing medical applications [64].

In the book written by Svon [3] it has been shown that three stages in the development of blockchain applications can be distinguished: Blockchain 1.0 when cryptocurrencies were used as cash resources in the payment systems; Blockchain 2.0 when the technology was used in the form of various applications (shares, obligations, credits, smart contracts, and so on); Blockchain 3.0 was used in blockchain applications in the field of public administration, healthcare, education, science, culture, and art.

There are more complicated classifications of the BT. For example, P. Durov presents the following criteria of classification [65]:

1) an architecture with a single or multiple block chain; 
2) consensus algorithm;

3 ) the type and rules of the blockchain elements: uniform, heterogeneous;

4) absence or presence of the main chain, internal or external;

5) interaction between the blockchains: loosely coupled or closely connected.

Ethereum and smart contracts occupy a special place in the BT [66]. Ethereum (from English ether) is a platform for creating decentralized blockchain-based online services working on the basis of smart contracts. Ethereum was created to execute the program code of any decentralized application. Unlike Bitcoin, it presents a wider set of accessible operations to the developer and enables him to create any programs. Thus, thousands of absolutely new applications can be realized in Ethereum [67].

A smart contract is the name of a computer code designed to organize the exchange of money, content, property, shares, or some other value. When run in the blockchain network the smart contract turns into a computer program automatically executed if some definite conditions are met. As the smart contract is running on top of a blockchain it works exactly as programmed: here no censorship, idle state, fraud, or intervention of the third party is possible $[66,67]$.

\section{Blockchain in medicine}

In the course of the initial search for the articles on the examined topic, 83 works were identified in the PubMed database and 75 publications in the eLibrary. A great number of reports were found in Internet: 50 publications appeared to be full-text magazine articles. It should be noted that new works, reports on startup organization, formation of research teams to study the possibilities of using the BT appear every day. The diversity of blockchain projects in the field of medicine today shows that far too many teams over the world make efforts to improve various aspects of this technology [68].

Presently, the main sphere of the BT application in medicine is electronic health cards (EHC). The system of $\mathrm{EHC}$ storage being developed in Russia will be arranged on the blockchain principle. It will be depersonalized meaning that data will be safely stored. The key will be individualized. The patient himself is supposed to decide who he wants to share the medical information with. This will be combined with the choice of the medical organization and general practitioner [69].

Several companies in the world are developing the technology of storage and access to patient medical records [70-84]. The Medicalchain startup project proposes the solution for digitization and safe storage of health cards in a blockchain ledger. The designers believe that this system will allow physicians, clinics, laboratories, and insurance companies to have access to the unified actual version of the health card excluding the possibility of loss or intended modification of the patient data [70].

Similar solution is proposed by blockchain-startup BurstIQ developing a uniform decentralized system for processing, storing, and transmitting data on the health of users and procedures related to it. In addition to the same services of managing individual health cards offered by Medicalchain, a BurstIQ platform provides the possibility to work with large arrays of data which is of special value to insurance companies and investigations in the field of medicine [71]. A distributed architecture model OmniPHR also pursues the objective to integrate personal health records as well as the entire medical information [72].

Guardtime company has created a BT-based system of patient personal identification. All users of this technology received smart cards which are connected with the EHC. When a patient visits a medical setting, hash is assigned to any update in the EHC and the data are recorded in the blockchain. This approach ensures that changes in the $\mathrm{EHC}$ records are safe and verifiable [73].

A MedRec platform proposes decentralized approach to the control of permissions, authorization, and common data usage in the system of healthcare. A blockchain in this application is designed for automated approach to a common use of data in clinical investigations. The authors of this conception declare that investigations in medicine will benefit from the use of the blockchain as this technology provides a fast and safe access to the necessary data [74].

DeepMind Technologies which is specializing in the artificial intelligence is developing a BT-based ledger of patient medical data for British hospitals. A special feature of these ledgers allows the system to provide secure data services under instructions of the hospital and data experts with the hospitals remaining in full control throughout. Using cryptographic tools the system will log any interactions with patient data. It will permit tracing the entire information about the corrections made in the ledger as well as about those who received access to patient data [75].

Doc.ai is a Russia startup which has combined the two most popular IT topics: the technology of artificial intelligence and the BT in the form of cryptocurrency. Doc.ai is planning to determine the physiological state of patients on request. An interactive system will communicate with a patient in a natural language, analyze genomic, pharmacogenomic, exposomic, anatomic data; the characteristics obtained from medical sensors; hematological data. Neuron tokens will provide access to the network and reward the users (individuals or research organizations).

Using tokens, users can arrange contests on the Neuron platform and create incentives (prizes) for specialists engaged in processing and analysis of medical data [76].

Open Longevity is one more Russian blockchain 
startup developing a system of disease diagnosis and interpretation of medical researches. They intend not only to give the users full information about their health but to carry out clinical investigations in therapy against aging involving patients in this process: some users will attract funds to the project, others (or the investors themselves) will voluntarily participate in strictly controlled medical tests. The startup assumes responsibility for entire legal work to provide the compliance with the strict international requirements to the investigations of this kind [77].

Robomed Network is a project dealing with the development of the system for making and supporting smart contracts between medical clinics and their patients. The information BT-based Robomed system unites medical providers and patients. The smart contracts are protocols intended for verifying or providing the execution of the contracts. The Robomed Network stores all data in the electron card, allows tracking the dynamics of changes, and a complete cycle of patient management. The system does not depend on the territorial distribution of clinics, all input data are collected in a single database. On the basis of the history taken by a physician, the Robomed Network forms instructions on the disease diagnosis, and as a result, the doctor establishes a diagnosis while the system gives recommendations for treatment. The doctor receives obligatory recommendations for patient treatment which he may correct at his own discretion [78]. The Robomed company has also developed a mobile application which enables anyone to undergo diagnostic procedures and start to receive treatment. A patient, clinic, and physician will interact directly through the smart contracts [79].

Owing to the BT integrated into the Doctor Smart service, a primary remote consultation with a physician will not be inferior (in quality and capabilities) to the direct communication with the doctor. All medical providers will be mandatory certified and these data will be accessible for all users and cannot be fictitious. Doctor Smart use the BT for financial transactions: all operations between the service clients and health providers are realized on the basis of tokens and smart contracts in Ethereum. The clients will be able to see prices for the services in the local currency and payment may be done on request by a bank card or using common electronic payment systems. Besides, Doctor Smart proposes acquisition and predictive analysis of information from wearable devices (e.g. fitness trackers). The service can perform continuous monitoring of the client's state of health, warn him about diseases, give advice on their prevention [79]. Similar approach is proposed by the designers of Bioritmai, a public system for body state control and early detection of cardiovascular diseases [80].

One more potentially valuable project is Gene Blockchain which focuses on the work with human genome. The company supply technologies and software products for sequencing and analysis of genetic sequences. On the basis of the project materials, the data obtained after the processing may be subsequently used for pathology diagnosis, selection of the appropriate drugs, and methods of treatment. Owing to the BT, the company is planning to make genetic investigation standard and less expensive [81].

A Russian company ARNA Genomics dealing with the problem of early detection of oncological diseases, is developing a biotechnological platform Arna Panacea based on the BT which will unite the participants of the medical research market. The platform intends to significantly reduce the terms of development introduction in the field of biotechnologies into the market, create a single protected storage of clinical data on oncological diseases, and provide open interaction between scientists, physicians, patients, pharmaceutical and insurance companies [82].

Advantages of using the BT in clinical investigations have been noted in the literature [83]. The BT allows clinical trials to be safely automated using smart contracts. At the same time, the technology provides thorough control of the data, their safety, and execution of common requirements both by a separate patient and all the participants of the clinical trials.

The BT can also be used to optimize the control and improve the efficacy of treatment due to the creation of the official ledger to track the quality of the components used in the production of pharmaceuticals and their distribution, and to provide prescription authenticity [84].

\section{Benefits and limitations of using blockchain in medicine}

The analysis of the literature allows the authors to speak of a great potential of using the BT in the healthcare system.

Decentralization. Blockchain may become a basis for decentralized control of medical data where all interested parties can control access to one and the same medical records and nobody will play the role of a central organ managing the global medical information.

Improved data safety and confidentiality. The attribute of blockchain immutability increases the safety of the data stored in it as the information saved in the blockchain cannot be damaged, changed, or restored. All medical data in the blockchain are encoded, time-stamped, and added in the chronological order. Besides, information on the health state is protected in the blockchain with cryptographic keys which help protect a person and confidentiality of patients.

Personal ownership of medical data. Patients must possess their data and control the way they are used. Patients must be sure that information about their health is not used by other interested party and they must have a tool to reveal cases of such misuse. The blockchain meets these requirements by means of reliable cryptographic protocols and strictly defined smart contracts. 
Accessibility and reliability. Since the logs in the blockchain are replicated in several nodes, accessibility of medical records stored there is guaranteed. The system is reliable and resistant against data loss, there damage, and some attacks on storage security.

Transparency and confidence. The blockchain creates an atmosphere of confidence around its healthcare applications owing to its open and transparent nature.

Data verifiability. It is possible to verify the integrity and validity of the records kept in the blockchain even without access to the open text. This function is very useful in the system of healthcare where record auditing is required, for example, to control the chain of pharmaceutical preparation delivery or analyze data on insurance requirements [8].

But there are also some limitations of using the blockchain in medicine. They are as follows [85-87]:

1) privacy of information - how to store all transactions in a common database without uncovering private information;

2) processing power - how to handle a large volume of transactions;

3) control - how to make decisions on updating protocols in a decentralized medium;

4) storage volume - how to store only minimal data volume to save the space in the blockchain;

5) responsibility - how to identify a guilty person in case of a conflict or error.

Problems in delineation of the access to information and fixation of its level also exist [88, 89].

The analysis conducted showed that a number of uneasy conditions should be fulfilled in order to use the BT in medicine:

1) to digitize all data and processes;

2 ) to have a sufficient number of specialists on cryptography;

3) to unify the rules for all participants;

4) to achieve transparency of the decisions made.

Blockchain as a technology is not amenable to regulation, only separate projects may be regulated (for example, storage and processing of personal and medical data, etc.) [90, 91]. The problem of quality control in rendering medical services has not been solved adequately in the BT $[92,93]$.

However, despite all limitations the BT becomes a widespread technology in medicine. A joint use of artificial intelligence (AI) and the BT is thought to be especially interesting direction for further development of the BT in the healthcare system. A great experience of using $\mathrm{Al}$ in different fields of medicine has been already accumulated [85, 94-98]. A great amount of individual data which can be processed with the help of Al may be generated in the distributed blockchain database. A blockchain-based smart system designed to support decision-making will precisely formulate a patient diagnosis by the results of the data analysis.
In terms of security, Al will simplify the work with blockchain. Neuron networks will be able to handle personal patient information directly in the encrypted form omitting intermediate stages of translation into the readable form. In this way, weak points and loopholes will be avoided during data processing [99].

The main issue in using $\mathrm{Al}$ in medicine is the difficulty of tracking the correctness of the decision made. The computation system operates with multiple variables and during the work teaches itself and generates new models. Therefore, there remains the necessity of human control of the artificial intelligence work. If all the decisions of the Al are reflected in the chain of blocks it will be always possible to verify whether the machine has chosen the right or erroneous way [99].

Classic computers use hashing algorithms to process the chain of blocks requiring great computational power. The attempt to use Al in this case will help to handle and encode information in a more rational and fast way. Self-teaching of the Al system will provide the opportunity to abandon the primitive methods of cryptography and enable the processing of the code in a new way [99].

\section{Conclusion}

Blockchain technologies become increasingly used in medicine and healthcare. They make it possible to transfer the work to the digital medium, digitize all data and work with all documents within the frame of a large global public information system. Though the majority of the projects are at the design stage, the results of their implementation will be evident in the near future. An interdisciplinary approach and collaboration of physicians with blockchain-specialists will provide the opportunity to use the rapidly evolving digital technologies in the field of medicine.

Study funding. The work was not supported by any financial source.

Conflicts of interest. The authors have no conflicts of interest to declare.

\section{References}

1. Nakamoto S. Bitcoin: a peer-to-peer electronic cash system. URL: https://bitcoin.org/bitcoin.pdf.

2. Savelyev I.E. Review article about the blockchain and its usage. Prikladnaya informatika 2016; 11(6): 19-24.

3. Svon M. Blokcheyn: skhema novoy ekonomiki [Blockchain: a scheme of the new economy]. Moscow: OlimpBiznes; 2016; 224 p.

4. Collins R. Blockchain: a new architecture for digital content. EContent 2016; 39(8): 22-23.

5. Chung M., Kim J. The internet information and technology research directions based on the fourth industrial revolution. KSII Transactions on Internet and Information Systems 2016; 10(3): 1311-1320, https://doi.org/10.3837/tiis. 2016.03.020. 
6. Underwood S. Blockchain beyond bitcoin. Commun ACM 2016; 59(11): 15-17, https://doi.org/10.1145/2994581.

7. Yli-Huumo J., Ko D., Choi S., Park S., Smolander K. Where is current research on blockchain technology? A systematic review. PLoS One 2016; 11(10), e0163477, https://doi.org/10.1371/journal.pone.0163477.

8. Agbo C.C., Mahmoud Q.H., Eklund J.M. Blockchain technology in healthcare: a systematic review. Healthcare 2019; 7(2): 56, https://doi.org/10.3390/healthcare7020056.

9. Crosby M., Nachiappan, Pattanayak P., Verma S., Kalyanaraman V. Blockchain technology: beyond bitcoin. Applied Innovation Review 2016; 2: 6-10.

10. Taylor P.J., Dargahi T., Dehghantanha A., Parizi R.M., Choo K.-K.R. A systematic literature review of blockchain cyber security. Digital Communications and Networks 2019, https:// doi.org/10.1016/j.dcan.2019.01.005.

11. Zhang Y., Wen J. The loT electric business model: using blockchain technology for the internet of things. Peer-to-Peer Networking and Applications 2017; 10(4): 983-994, https://doi. org/10.1007/s12083-016-0456-1.

12. Mogayar U., Buterin V. Blokcheyn dlya biznesa [Blockchain for business]. Moscow: Eksmo; 2017: 224 p.

13. Krasikova E.M. Blockchain: technology of the future. Alleya nauki 2018; 1(1): 219-224.

14. Sadullaev H.H.U. The seven design principles of a blockchain economy. Alleya nauki 2018; 3(1): 911-913.

15. Melnychenko O., Hartinger R. Role of blockchain technology in accounting and auditing. European Cooperation 2017; 9(28): 27-34.

16. Knezevic D. Impact of blockchain technology platform in changing the financial sector and other industries. Montenegrin Journal of Economics 2018; 14(1): 109-120, https://doi. org/10.14254/1800-5845/2018.14-1.8.

17. Biktimirov M.R., Domashev A.V., Cherkashin P.A., Shcherbakov A.Y. Blockchain technology: universal structure and requirements. Automatic Documentation and Mathematical Linguistics 2017; 51(6): 235-238, https://doi.org/10.3103/ s0005105517060036.

18. Pilkington M. Blockchain technology: principles and applications. In: Olleros F.X., Zhegu M. (editors). Research handbook on digital transformations. Edward Elgar Publishing; 2016; p. 225-253, https://doi.org/10.4337/9781784717766. 00019.

19. Tapscott D., Tapscott A. Blockchain revolution: how the technology behind bitcoin is changing money, business, and the world. New York: Penguin; 2016; $386 p$.

20. Sharples M., Domingue J. A distributed system for educational record, reputation and reward. In: Adaptive and adaptable learning. Springer, Cham; 2016; p. 490-496, https:// doi.org/10.1007/978-3-319-45153-4_48.

21. Chasovskikh V.P., Labunets V.G., Voronov M.P. Blockchain technology in education of universities and the digital economy. Eko-potentsial 2017; 2(18): 99-105.

22. Skiba D.J. The potential of blockchain in education and health care. Nursing education perspectives 2017; 38(4): 220 221, https://doi.org/10.1097/01.nep.0000000000000190.

23. Hoy M.B. An introduction to the blockchain and its implications for libraries and medicine. Medical reference services quarterly 2017; 36(3): 273-279, https://doi.org/10.108 0/02763869.2017.1332261.

24. De la Rosa J., Torres-Padrosa V., El-Fakdi A., Gibovic D., Hornyák O., Maicher L., Miralles F. A survey of blockchain technologies for open innovation. In: Proceedings of the $4^{\text {rd }}$ Annual World Open Innovation Conference, WOIC 2017. San Francisco, USA; 2017. URL: http://eia.udg. edu/ aelfakdi/papers/woic17.pdf.

25. Tao X. Research on the development and significance of "Blockchain+" education. Journal of Distance Education 2017; 2: 003.

26. Dettling W. How to teach blockchain in a business school. In: Business information systems and technology 4.0. Springer, Cham; 2018; p. 213-225, https://doi. org/10.1007/978-3-319-74322-6_14.

27. Gaetani E., Aniello L., Baldoni R., Lombardi F., Margheri A., Sassone V. Blockchain-based database to ensure data integrity in cloud computing environments. In: Proceedings of the First Italian Conference on Cybersecurity (ITASEC17). Venice, Italy; 2017; p. 146-155. URL: http://ceurws.org/Vol-1816/paper-15.pdf.

28. Rimba P., Tran A.B., Weber I., Staples M., Ponomarev A., $\mathrm{Xu} \mathrm{X}$. Comparing blockchain and cloud services for business process execution. In: IEEE International Conference on Software Architecture, ICSA 2017. Gothenburg, Sweden; 2017; p. 257-260, https://doi.org/10.1109/icsa.2017.44.

29. Kshetri N. Can blockchain strengthen the internet of things? IT Professional 2017; 19(4): 68-72, https://doi. org/10.1109/mitp.2017.3051335.

30. Ayed A.B. A conceptual secure blockchain-based electronic voting system. International Journal of Network Security \& Its Applications 2017; 9(3): 1-9, https://doi. org/10.5121/ijnsa.2017.9301.

31. Lee K., James J.I., Ejeta T.G., Kim H.J. Electronic voting service using block-chain. Journal of Digital Forensics, Security and Law 2016; 11(2), https://doi.org/10.15394/jdfsl.2016.1383.

32. Noizat P. Blockchain electronic vote. In: Chuen D.L.K. (editor). Handbook of digital currency. Bitcoin, innovation, financial instruments, and big data. Elsevier; 2015; p. 453-461, https://doi.org/10.1016/b978-0-12-802117-0.00022-9.

33. Shrier D., Wu W., Pentland A. Blockchain \& infrastructure (identity, data security). Massachusetts Institute of Technology, MIT Connection Science; 2016. URL: https:// www.getsmarter.com/blog/wp-content/uploads/2017/07/mit blockchain_and_infrastructure_report.pdf.

34. Zeilinger M. Digital art as "Monetised Graphics": enforcing intellectual property on the blockchain. Philosophy \& Technology 2018; 31(1): 15-41, https://doi.org/10.1007/ s13347-016-0243-1.

35. Tsai W.T., Feng L., Zhang H., You Y., Wang L., Zhong Y. Intellectual-property blockchain-based protection model for microfilms. In: IEEE International Symposium on ServiceOriented System Engineering (SOSE). San Francisco, USA; 2017; p. 174-178, https://doi.org/10.1109/sose.2017.35.

36. Blokcheyn [Blockchain]. URL: https://ru.wikipedia.org/ wiki/Блокчейн.

37. Onlayn-kurs po Blockchain [Blockchain online course]. URL: https://distributedlab.com/online-course.

38. Popper N. Tsifrovoe zoloto. Neveroyatnaya istoriya Bitkoyna, ili kak idealisty i biznesmeny izobretayut den'gi zanovo [Digital gold. Incredible story of Bitcoin, or how idealists and businessmen invent money anew]. Moscow: Dialektika; 2018; 368 p.

39. Vigna P., Kasey M. Epokha kriptovalyut. Kak bitkoin i blokcheyn menyayut mirovoy ekonomicheskiy poryadok [The age of cryptocurrency. How bitcoin and the blockchain are challenging the global economic order]. Moscow: Mann, Ivanov i Ferber; 2017; 432 p. 
40. Rikards D. Zolotoy zapas. Pochemu zoloto, a ne bitkoiny - valyuta XXI veka? [Gold reserves. Why gold, not Bitcoins, is the currency of the XXI century?]. Moscow: Eksmo; 2017; 192 p.

41. Raval S. Detsentralizovannye prilozheniya. Tekhnologiya blockchain $v$ deystvii [Decentralized applications. Blockchain technology in action]. Saint Petersburg: Piter; 2017; 240 p.

42. Antonopoulos A.M. The Internet of money. Merkle Bloom LLC; 2016; 150 p.

43. Champagne P. The book of Satoshi: the collected writings of bitcoin creator Satoshi Nakamoto. USA: e53 Publishing LLC; 2014; 394 p.

44. Mannaro K., Pinna A., Marchesi M. Crypto-trading: blockchain-oriented energy market. In: AEIT International Annual Conference. Cagliari, Italy; 2017, https://doi. org/10.23919/aeit.2017.8240547.

45. Akulich M. Blockchain dlya marketinga [Blockchain for marketing]. 2019. URL: https://fictionbook.ru/author/margarita_ akulich/blockchain_dlya_marketinga/read_online.html.

46. Sikorski J.J., Haughton J., Kraft M. Blockchain technology in the chemical industry: machine-to-machine electricity market. Applied Energy 2017; 195: 234-246, https:// doi.org/10.1016/j.apenergy.2017.03.039.

47. Zaslavsky A.A. Prospects for the use of blockchain algorithms to ensure security in the management of the educational organization. Vestnik Rossiyskogo universiteta druzhby narodov. Seriya: Informatizatsiya obrazovaniya 2018; 15(1): 101-106, https://doi.org/10.22363/2312-8631-2018-15-1101-106.

48. Borioli G.S., Couturier J. How blockchain technology can improve the outcomes of clinical trials. British Journal of Healthcare Management 2018; 24(3): 156-162, https://doi. org/10.12968/bjhc.2018.24.3.156.

49. Roman-Belmonte J.M., De la Corte-Rodriguez H., Rodriguez-Merchan E.C. How blockchain technology can change medicine. Postgrad Med 2018; 130(4): 420-427, https://doi.org/10.1080/00325481.2018.1472996.

50. Hoy M.B. An introduction to the blockchain and its implications for libraries and medicine. Med Ref Serv Q 2017; 36(3): 273-279, https://doi.org/10.1080/02763869.2017.1332261.

51. Dubovitskaya A., Xu Z., Ryu S., Schumacher M., Wang F. How blockchain could empower e-health: an application for radiation oncology. In: Begoli E., Wang F., Luo G. (editors). Data management and analytics for medicine and healthcare. DMAH 2017. Lecture notes in computer science. Springer, Cham; 2017; p. 3-6, https://doi. org/10.1007/978-3-319-67186-4_1.

52. Rabah K. Challenges \& opportunities for blockchain powered healthcare systems. A review. Mara Research Journal of Medicine \& Health Sciences 2017; 1(1): 45-52.

53. Liu P.T.S. Medical record system using blockchain, big data and tokenization. In: Lam K.-Y., Chi C.-H., Qing S. (editors). Information and communications security. ICICS 2016. Lecture notes in computer science. Springer, Cham; 2016; p. 254-261, https://doi.org/10.1007/978-3-319-50011-9_20.

54. Dubovitskaya A., Novotny P., Xu Z., Wang F. Applications of blockchain technology for data-sharing in oncology: results from a systematic literature review. Oncology 2019; 3: 1-9, https://doi.org/10.1159/000504325.

55. Huckle S., Bhattacharya R., White M., Beloff N. Internet of things. Blockchain and shared economy applications. Procedia Computer Science 2016; 98: 461-466, https://doi. org/10.1016/j.procs.2016.09.074.
56. Kulikov N.I., Kudryavtseva Yu.V. Banks on the threshold of the new technological revolution. Voprosy sovremennoy nauki i praktiki 2017; 2(64): 69-78.

57. Pazaitis A., De Filippi P., Kostakis V. Blockchain and value systems in the sharing economy: the illustrative case of backfeed. Technological Forecasting and Social Change 2017; 125: 105-115, https://doi.org/10.1016/j.techfore.2017.05.025.

58. Alexandrikova I., Kozlova E. Bitcoin as a new instrument of financial services. Teoriya i praktika sovremennoy nauki 2017; 6(24): 48-51.

59. Lelu L. Blokcheyn ot $A$ do Ya: vse o tekhnologii desyatiletiya [Blockchain from A to Z: all about technology of the decade]. Moscow: Bombora; 2018; 256 p.

60. Dresher D. Osnovy blokcheyna [Blockchain basics]. Moscow: DMK Press; 2018; 312 p.

61. Popov V. Blokcheyn filosofiya [Blockchain philosophy]. 2018. URL: https://www.litres.ru/vladimir-popov-7629101/ blokcheyn-filosofiya-chast-i.

62. Shuaib K., Saleous H., Shuaib K., Zaki N. Blockchains for secure digitized medicine. J Pers Med 2019; 9(3): 35, https://doi.org/10.3390/jpm9030035.

63. Kraft D. Difficulty control for blockchain-based consensus systems. Peer-to-Peer Networking and Applications 2016; 9(2): 397-413, https://doi.org/10.1007/s12083-015-0347-x.

64. Kuo T.T., Kim H.E., Ohno-Machado L. Blockchain distributed ledger technologies for biomedical and health care applications. J Am Med Inform Assoc 2017; 24(6): 1211-1220, https://doi.org/10.1093/jamia/ocx068.

65. Telegram open network. URL: https://ru.ton-telegram. net/.

66. Dannen C. Introducing Ethereum and Solidity. Foundations of cryptocurrency and blockchain programming for beginners. New York, Apress; 2017; 185 p., https://doi. org/10.1007/978-1-4842-2535-6.

67. Diedrich H. Ethereum: blockchains, digital assets, smart contracts, decentralized autonomous organizations. Create Space Independent Publishing Platform; 2016; 360 p.

68. Tsyganov S.N., Tugolukova A.V. Vozmozhnosti primeneniya tekhnologii blokcheyn $\vee$ zdravookhranenii. $\mathrm{V} \mathrm{kn}$.: Perspektivy razvitiya nauki i obrazovaniya [The possibilities of using blockchain technology in healthcare. In: Prospects for the development of science and education]. Moscow: IP Tugolukov A.V.; 2017; p. 123-126.

69. URL: https://vademec.ru/news/2017/09/06/elektronnyemeditsinskie-karty-rossiyan-budut-khranit-po-printsipublokcheyn/.

70. Blokcheyn dlya elektronnykh meditsinskikh kart [Blockchain for electronic medical records]. URL: https:// medicalchain.com/ru/.

71. Burst/Q Receives Frost \& Sullivan 2019 Best Practice Award for Healthcare Data Management. URL: https:// finance.yahoo.com/news/burstiq-receives-frost-sullivan-2019133000808.html.

72. Roehrs A., da Costa C.A., da Rosa Righi R. OmniPHR: a distributed architecture model to integrate personal health records. J Biomed Inform 2017; 71: 70-81, https://doi. org/10.1016/j.jbi.2017.05.012.

73. Yoon H.J. Blockchain technology and healthcare. Healthcare Informatics Research 2019; 25(2): 59-60, https:// doi.org/10.4258/hir.2019.25.2.59.

74. Azaria A., Ekblaw A., Vieira T., Lippman A. MedRec: using blockchain for medical data access and permission management. In: International Conference on Open and Big 
Data (OBD). Vienna, Austria; 2016, https://doi.org/10.1109/ obd.2016.11.

75. Trust, confidence and verifiable data audit. URL: https:// deepmind.com/blog/trust-confidence-verifiable-data-audit/.

76. Doc.ai. URL: https://doc.ai.

77. Open Longevity. Klinicheskie issledovaniya po initsiative patsientov [Clinical trials initiated by patients]. URL: https://medium.com/open-longevity/.

78. Robomed. URL: https://robo-med.com.

79. Doctor Smart. URL: http://doctorsmart.vc/ru.

80. Bioritm-braslet [Biorhythm bracelet]. URL: https://www. tokendesk.io/ico/bioritmai.

81. Zenome. A first decentralized Internet of genomic data and services. URL: https://zenome.io/.

82. ARNA genomics. URL: https://arna.bio/en/.

83. Benchoufi M., Ravaud P. Blockchain technology for improving clinical research quality. Trials 2017; 18(1): 335, https://doi.org/10.1186/s13063-017-2035-z.

84. Baunm S. Health IT startups working to secure pharma supply chains? URL: http://medcitynews.com/2017/01/drugsupply-chain-security-and-technology/.

85. Hussien H.M., Yasin S.M., Udzir S.N., Zaidan A.A., Zaidan B.B. A systematic review for enabling of develop a blockchain technology in healthcare application: taxonomy, substantially analysis, motivations, challenges, recommendations and future direction. J Med Syst 2019; 43(10): 320, https://doi.org/10.1007/s10916-019-1445-8.

86. Belyaev A.M., Stilidi I.S., Kaprin A.D., Lichinitser M.R., Mescheryakov A.A., Semiglazov V.F., Imyanitov E.N., Semiglazova T.Yu., Poltoratsky A.N., Konstantinov L.V., Petrusenko I.A., Nikitin O.I., Zakharov K.A., Trifonov M.I., Plakhov D.N. Blockchain in health care: opportunities for use in clinical trials. Lechebnoe delo 2018; 2: 100-105.

87. Chang M.C., Hsiao M.Y., Boudier-Revéret M. Blockchain technology: efficiently managing medical information in the pain management field. Pain Med 2019, https://doi.org/10.1093/pm/pnz261.

88. Bhattacharya S., Singh A., Hossain M.M. Strengthening public health surveillance through blockchain technology. AIMS Public Health 2019; 6(3): 326-333, https://doi.org/10.3934/ publichealth.2019.3.326.

89. Johnson M., Jones M., Shervey M., Dudley J.T., Zimmerman N. Building a secure biomedical data sharing decentralized app (DApp): tutorial. J Med Internet Res 2019; 21(10): e13601, https://doi.org/10.2196/13601.

90. Balis C., Tagopoulos I., Dimola K. Moving towards a blockchain-based healthcare information system. Stud Health Technol Inform 2019; 262: 168-171, https://doi.org/10.3233/ SHTI190044.

91. Mackey T.K., Kuo T.T., Gummadi B., Clauson K.A., Church G., Grishin D., Obbad K., Barkovich R., Palombini M. 'Fit-for-purpose?' - challenges and opportunities for applications of blockchain technology in the future of healthcare. BMC Med 2019; 17(1): 68, https://doi.org/10.1186/ s12916-019-1296-7.

92. Kuo T.T., Zavaleta Rojas H., Ohno-Machado L. Comparison of blockchain platforms: a systematic review and healthcare examples. J Am Med Inform Assoc 2019; 26(5): 462-478, https://doi.org/10.1093/jamia/ocy185.

93. Drosatos G., Kaldoudi E. Blockchain applications in the biomedical domain: a scoping review. Comput Struct Biotechnol J 2019; 17: 229-240, https://doi.org/10.1016/j. csbj.2019.01.010.

94. Litvin A.A., Litvin V.A. Clinical decision support systems for surgery. Novosti khirurgii 2014; 22(1): 96-100.

95. Clinical decision support: the road ahead. Greenes R.A. (editor). Boston: Elsevier Academic Press; 2007; 581 p.

96. O'Donoghue O., Vazirani A.A., Brindley D., Meinert E. Design choices and trade-offs in health care blockchain implementations: systematic review. J Med Internet Res 2019; 21(5): e12426, https://doi.org/10.2196/12426.

97. Kobrinsky B.A. Decision support systems in public health services and training. Vrach $i$ informatsionnye tekhnologii 2010; 2: 39-45.

98. Krittanawong C., Rogers A.J., Aydar M., Choi E., Johnson K.W., Wang Z., Narayan S.M. Integrating blockchain technology with artificial intelligence for cardiovascular medicine. Nat Rev Cardiol 2019, https://doi.org/10.1038/ s41569-019-0294-y.

99. Mamoshina P. Ojomoko L., Yanovich Y., Ostrovski A., Botezatu A., Prikhodko P., Izumchenko E., Aliper A., Romantsov K., Zhebrak A., Ogu I.O., Zhavoronkov A. Converging blockchain and next-generation artificial intelligence technologies to decentralize and accelerate biomedical research and healthcare. Oncotarget 2018; 9(5): 5665-5690, https://doi.org/10.18632/oncotarget.22345. 